\title{
0 ensino da gramática na educação básica: desafios e problemáticas
}

\author{
Rosana Passos Quitério de Carvalho' \\ Rita de Cássia Olivério Couto²
}

\begin{abstract}
1.Rosana Passos Quitério de Carvalho. Especialização em Psicopedagogia, Libras, Gramática e texto da Língua Portuguesa pela Universidade Nove de Julho. Graduada em Pedagogia pela Universidade de Guarulhos, é professora da rede municipal de Guarulhos e das Faculdades Eniac de Guarulhos.

2.. Mestre em Semiótica das Literaturas pela mesma universidade. Bacharel em Língua e Literatura Portuguesa pela Pontifícia Universidade Católica, de São Paulo exerce, atualmente, a docência superior como professora do Centro Universitário Nove de Julho (São Paulo), tanto em nível de graduação como de pós-graduação lato sensu. Coordena, na mesma instituição de ensino, o Projeto Sementeira, voltado para desenvolvimento da leitura e divulgação da literatura infanto-juvenil. Faz parte do grupo de estudos Lingüística e Literatura: Teoria e Práticas Discursivas, certificado pelo CNPq.
\end{abstract}

\section{Resumo}

Através de pesquisa bibliográfica, o presente trabalho busca abordar os desafios e problemas observados no ensino da gramática da educação básica da rede pública de ensino. Para tanto, parte-se da diversidade de linguagens utilizadas pelos alunos e do despreparo da escola para lidar com essa situação, com programas e professores antigos e inadequados para essa realidade. Os autores Travaglia (2006) e Cagliari (2009) servirão de base teórica para esta reflexão, além da contribuição de outros pesquisadores de igual importância.

Palavras-chave: gramática, diversidade de linguagens e ensino da Língua Portuguesa.

\begin{abstract}
Based on a bibliographic research, the present work approaches the challenges and problems noticed on teaching grammar at the basic education of the public schools. Accordingly, we start with the diversity of languages used by students and the unpreparedness of the school to deal with such a situation - with programmes and teachers inappropriate and ancient to that reality. The authors Travaglia (2006) and Cagliari (2009) base our theoretic reflection, in addition to the contribution of some others researchers equally important.
\end{abstract}

Keywords: Grammar; Diversity of Languages; Portuguese Language Teaching.

\section{Introdução}


Considerando-se as inúmeras discussões em torno da importância do ensino da gramática, este trabalho tem por objetivo analisar as abordagens que têm sido feitas sobre este assunto nas escolas de educação básica da rede pública. Com base, principalmente, nos autores Travaglia (2006) e Cagliari (2009), a presente pesquisa fará uma reflexão acerca do assunto, servindo-se dos estudos, pesquisas e argumentos disponibilizados em suas obras.

Para alcançar os objetivos propostos com esta pesquisa foi utilizado o método bibliográfico, buscando na teoria, os alicerces necessários para sustentar a necessidade e a importância do ensino reflexivo da gramática, considerando sua importância para a preparação plena do indivíduo na sociedade.

A escolha por esse assunto partiu da convivência com a necessidade constante de buscar alternativas que potencializassem o aprendizado dos alunos em sala, já que existe, em muitos casos, grande distância entre a realidade em que vivem e a sala de aula.

Neste estudo discutem-se algumas ações em sala de aula, bem como as exigências presentes nos Parâmetros Curriculares Nacionais (PCN's), refletindose a respeito da eficiência e utilização correta dessas ações.

\section{A realidade linguística da criança}

$\mathrm{Na}$ escola, quando a criança será estimulada para se alfabetizar, ela já é capaz de se comunicar facilmente na sua língua materna, ou seja, entende e fala a língua portuguesa.

Quando se diz que essa criança é um usuário da língua, deve-se considerar que ela possui um vocabulário e algumas regras gramaticais que permitem que ela se comunique de maneira compreensível com as outras crianças, seus familiares e professores.

De acordo com Cagliari ${ }^{1}$, a linguagem é um fato social e sobrevive graças às convenções sociais que são admitidas para ela. As pessoas falam como seus semelhantes e por isso se entendem. Com base nesses argumentos, conclui-se que se cada um falasse do jeito que quisesse, as pessoas não se entenderiam e, consequentemente, não poderiam se comunicar.

Ainda nessa abordagem, não se pode deixar de citar os dialetos, que, embora sejam inúmeros e presentes em nosso país, assim como em qualquer outro, são modos diferentes de falar, mas que ainda assim, fazem uso da gramática normativa.

Como exemplo dessa situação, podemos citar a maneira de falar de um caipira, comparada com um paulistano. "Nóis

${ }^{1}$ CAGLIARI, Luiz Carlos. Alfabetização e Linguística. $1^{\text {a }}$ Edição.São Paulo: Scipione, 2009. Pg. 16. 
vai cumê" pode ser dito pelo caipira e embora esteja em desacordo com a pronúncia correta das palavras, não alteram a ordem da sentença, dando o significado correto a ela.

Cagliari (2009), afirma que no Brasil não existe um português de rainha ou imperador, como acontece no Reino Unido, e ainda completa:

\footnotetext{
Observando o comportamento da sociedade, nota-se que em São Paulo, por exemplo, há um modo de falar que goza de grande prestígio e vários outros modos que, em graus diferentes, são estigmatizados, chegando-se ao dialeto caipira, que o é em maior grau. No Rio de Janeiro, há um modo de falar que é considerado de prestígio, mas que é diferente do modo de falar de prestígio em São Paulo. (CAGLIARI, 2009, pg 75)
}

Por isso, a escola precisa conhecer e entender essa realidade linguística, para que não cometa injustiças com seus alunos, comprometendo o processo de educação a que se propõe.

Uma criança oriunda de uma comunidade pobre, que fala um dialeto diferente do utilizado na escola, pode sentirse excluída e em desacordo com aquele lugar, provavelmente vindo a conhecer o preconceito e a discriminação. A escola, além de interpretar de forma errada a

2 Ibid, pg 75 . realidade da criança, não demonstra nenhuma preocupação com ela, pois já tem seus currículos prontos e decididos provavelmente por pessoas que desconhecem essa realidade.

Segundo os PCN's da língua portuguesa $^{3}$, os conhecimentos gramaticais devem ser inseridos a partir da realidade do aluno e da sua necessidade, com a finalidade de aprimorar sua capacidade de utilização da língua. Além disso, conhecer bem os conceitos de substantivo, adjetivo, verbo e tantos outros existentes, não é garantia de produção de bons textos, isto porque os aspectos gramaticais a serem trabalhados devem ser selecionados a partir da produção escrita dos alunos.

Isso significa que o aprendizado só poderá acontecer se estiver diretamente relacionado à sua utilidade, embora isto não seja um privilégio dos conteúdos da língua portuguesa, já que essa afirmação está presente em diversas outras áreas.

De acordo com Palomo (2002) $)^{4}$ a linguagem utilizada na escola é monológica, por atuar como se ignorasse o fenômeno da interação verbal, dificultando, com isso, sua função essencial, a comunicação. Com isso, o ponto de partida

\footnotetext{
${ }^{3}$ http:/ / portal.mec.gov.br/seb/arquivos/pdf/livro02.pdf/ pg. 60, Acesso em: 14 jan 2013

http://www4.uninove.br/ojs/index.php/dialogia/article/vi ewFile/847/727, pg 111. Acesso em 16 jan 2013
} 
de toda essa discussão será a comunicação, seja ela verbal ou escrita, pois é através desse fenômeno que o indivíduo irá se relacionar na sociedade.

A linguística é o estudo científico da linguagem, com foco na explicação de como a linguagem humana funciona. Por tradição, costumava-se estudar uma língua através de sua gramática normativa e do dicionário. Mas isso deixou de ser suficiente, visto que uma língua é muito mais do que isto, embora sua importância seja relevante e não pode ser menosprezada.

Sendo a língua uma forma de expressão humana, ela acaba servindo como ligação entre o homem e o mundo que o cerca, ou seja, é o instrumento de comunicação entre eles, já que é utilizada apenas por seres racionais, que, inclusive, são os únicos que podem desenvolver uma linguagem verbal.

A linguagem, por sua vez, ramifica-se em diversos tipos, como por exemplo, gestual, musical e simbólica, não existindo sociedade sem linguagem.

Os modos diferentes de falar ocorrem porque as línguas sofrem modificações ao longo do tempo, já que é viva e está em uso constante. Mesmo com essas modificações as línguas não se degeneram, apenas adquirem novos valores, já que estão diretamente ligados às novas perspectivas da sociedade.

Dentro desse contexto, a escola incorpora os conceitos de certo e errado, compartilhando as marcas sociais geradas pelo modo de falar das pessoas, rotulando assim seus alunos. Para aceitar essa variação linguística, a escola precisa mudar sua visão, respeitando os dialetos, entendendo-os e ensinando como as variações da língua funcionam.

Para Cagliari $(2010)^{5}$, a escola leva o aluno a pensar que a linguagem correta é a linguagem escrita, transmitindo uma ideia falsa do que realmente acontece, já que a escrita tem aspectos que a linguagem oral não usa: são diferentes, cada um com suas finalidades específicas.

Pode-se considerar importante também dentro desse ambiente, mostrar aos alunos que a sociedade atribui valores sociais diferentes aos diferentes modos de falar a língua, gerando preconceitos e falsas interpretações de certo e errado, bem como as consequências dessas ações.

Portanto, aprender português não significa aprender somente como a língua funciona, mas também as formas como ela pode ser usada, aprender efetivamente as variações linguísticas. Fazendo isso, a escola

${ }^{5}$ CAGLIARI, Luiz Carlos. Alfabetização e Linguística. $1^{\text {a }}$ Edição.São Paulo: Scipione, 2009. Pg. 32 
estará cumprindo seu papel de proporcionar aos indivíduos menos favorecidos, a possibilidade de promovê-los socialmente, com compreensão do mundo ao seu redor.

\section{O ensino da gramática na escola} regular

As diferenças entre a linguagem coloquial e a linguagem culta podem ser melhor compreendidas se estiverem sob a luz das condições gerais de uso dessas linguagens. Segundo Kato $(2005)^{6}$, a fala é regida por imposições de ordem comunicacional $e$ funcional, enquanto a escrita sofre imposições de ordem normativa e convencional.

Isto significa que para se comunicar, na maioria das vezes, o indivíduo precisa de praticidade e objetividade, e a escrita tem suas regras e convenções que não podem ser ignoradas em nenhuma circunstância. Com isto, chegamos em um importante ponto de discussão: como a escola deve agir, considerando esse ambiente antagônico e ao mesmo tempo uníssono?

Travaglia $(1996)^{7}$, propõe o ensino da gramática na escola com atividades que

\footnotetext{
${ }^{6}$ KATO, Mary A. No mundo da escrita: uma perspectiva psicolinguística. 7 edição. São Paulo: editora Ática, 2005, pg 28.

7 TRAVAGLIA, Luiz Carlos. Ensino de gramática em uma perspectiva textual-interativa e qualidade de vida. Disponível

http://www.mel.ileel.ufu.br/homepages/travaglia/artigos/ artigo ensino gramatica perspectiva _qualidade_vida.pdf. Acesso em 14 jan 2013.
}

propiciem aos alunos efetiva preparação para suas vidas presente e futura, com uma visão da língua como atuação social e exercício da cidadania. Isto reforça a ideia de "ensinar para a vida", altamente relacionado à prática e à utilização do que se aprende, dando significado ao conteúdo a ser ensinado.

Para que um indivíduo possa moverse e atuar dentro de uma sociedade, ele precisa de instrumentos e ferramentas que lhe proporcionem atuar com segurança $e$ competência dentro desse ambiente, e é aí que a escola precisa mostrar-se engajada e envolvida nesse processo, já que, somente assim ela será capaz de contribuir com o desenvolvimento da competência comunicativa dessa pessoa.

De acordo com Travaglia (2006) ${ }^{8}$, há uma ausência muito grande de atividades que envolvem produção e compreensão de textos, o que poderia ser de grande valia para auxiliar no desenvolvimento da competência comunicativa.

Infelizmente, a escola tem tratado o ensino da gramática de forma separada do texto, fazendo com que o aluno não encontre sentido nesse aprendizado e que tal conteúdo não represente nenhum significado em sua vida.

8 TRAVAGLIA, Carlos Luiz. Gramática e Interação: uma proposta para o ensino de gramática. 11. Ed. São Paulo: Cortez, 2006. 
Por outro lado, o professor sente-se distante desse mesmo aluno, porque não consegue atingi-lo de maneira eficiente, aumentando mais ainda a ideia de que o que se aprende na escola não serve para a vida.

Esse quadro somente poderá ser revertido, se a escola for capaz de reaproximar texto e gramática novamente, privilegiando a função que as estruturas lexicogramaticais cumprem no texto, e os sentidos que produzem.

Ampliar a competência discursiva deve ser o objetivo central da escola ao tratar o ensino da língua portuguesa a seus alunos. Porém, essa necessidade acaba sendo prejudicada quando atingimos a discussão em torno da prática pedagógica a ser utilizada.

Por isso, é preciso de uma vez por todas desenvolver um trabalho pedagógico que promova a necessária aproximação entre gramática e texto, devendo o foco das aulas de língua portuguesa na escola básica não ser a gramática com fim e objetivo em si mesma.

A proposta de trabalho com textos tem como principal conteúdo os diversos gêneros, rotineiramente inseridos nas atividades, observando e registrando suas características, estrutura e contexto, e percebendo como eles são construídos e por que assim o são. Portanto, é exatamente por essa estreita relação entre a gramática e a construção de textos que não se pode admitir estudar uma língua sem considerar sua gramática.

\section{1 - como ensinar a gramática?}

Explorar as possibilidades da língua tem como fim a compreensão e a construção de textos. Segundo DUTRA (2011) ${ }^{9}$, a análise linguística é meramente meio para se chegar à construção dos sentidos do texto, fim que deveria ser perseguido nas aulas de língua.

Dessa forma, o texto deve ser a unidade básica de estudo da língua, e dentro desse contexto pode-se alocar o lugar da gramática:

'Um texto é uma unidade semântica, não gramatical. Mas os significados são realizados por fraseados; e sem uma teoria dos fraseados - isto é, uma gramática - não há maneira de tornar explícita a interpretação que se far do sentido de um texto. Assim, o atual interesse na análise do discurso está de fato provendo um contexto dentro do qual a gramática tem um lugar central." $(H A L L I D A Y, 2004)^{10}$

\footnotetext{
9 DUTRA, Vânia Lúcia Rodrigues. Abordagem funcional da gramática na escola básica. Anais do VII Congresso Internacional de Abralin. Curitiba, 2011. Disponível em: http://www.abralin.org/abralin11 _cdrom/artigos/Vania_Dutra.PDF. Acesso em 10 jan 2013.

${ }^{10}$ HALLIDAY, M. A. K. An introduction to functional grammar. London: Edward Arnold, 2004.
} 
$\mathrm{Na}$ educação básica é preciso refletir sobre o funcionamento da língua nas situações cotidianas e nos diversos ambientes sociais, envolvendo com isso, os dialetos, sua utilização e as exigências da sociedade para uma boa comunicação. Voltando a citar o preconceito e a exclusão sofrida por alguns alunos dentro da escola, ratificamos a eficiência de levarmos todos esses aspectos em consideração para ensinar gramática de forma natural, mostrando sua importância no desenvolvimento da competência comunicativa dos alunos.

As atividades linguísticas são aquelas que o usuário da lingua (falante, escritor, ouvinte, leitor) faz ao buscar estabelecer uma interação comunicativa por meio da língua e que the permite ir construindo o seu texto de modo adequado à situação, aos seus objetivos comunicacionais, ao desenvolvimento do tópico discursivo que alguns chamam de assunto ou tema. ${ }^{11}$

Priorizar o ensino da gramática voltada para o uso linguístico, levando o aluno a refletir sobre o uso da linguagem nas diversas situações, fará com que os alunos entrem em contato com o real uso da linguagem, fugindo da ineficiente realidade de ensinar por ensinar conceitos gramaticais isolados e sem função.

\footnotetext{
11 TRAVAGLIA, Carlos Luiz. Gramática e Interação: uma proposta para o ensino de gramática. 11. Ed. São Paulo: Cortez, 2006, p. 33-34.
}

Se a escola não ampliar sua visão e reavaliar seus horizontes de atuação, continuará a focar seu trabalho na língua escrita, voltando-se, principalmente, para a norma culta da língua. Isto levará, cada vez mais, seus alunos na direção de que a escola ensina “coisas que não são úteis", pois as pessoas não falam daquele jeito, portanto, esses conteúdos não terão utilidade.

Os alunos devem ser levados a refletir, por exemplo, que o uso de uma linguagem mais objetiva, com a presença de códigos específicos e palavras abreviadas, podem ser usados em uma conversa informal, com amigos, em uma bate papo na internet. Porém, se ele precisar se comunicar com alguém desconhecido ou que não faz parte do mesmo núcleo de relacionamento, ele precisará ser mais formal e utilizar a escrita normal das palavras.

Infelizmente, a escola tem falhado neste papel e isto inclui também a metodologia utilizada pelo professor em sala de aula. Se essa abordagem não for feita, as produções desses alunos continuarão compostas de linguagem inadequada em ambientes inadequados, porque ela relação não está clara para seu usuário.

\section{Considerações finais}

Com base na pesquisa bibliográfica realizada, pode-se observar que, de acordo $\underline{\text { www.fics.edu.br } 7}$ 
com os autores citados, ainda temos uma escola tradicional, que busca o ensino da gramática normativa ligado a um sistema antigo e desatualizado.

O professor de português tem que ser um profissional competente, conhecer profundamente a língua portuguesa e sua utilização. Se continuarem a ignorar a linguística e agir como há cem anos, reproduzirão os mesmos tantos erros já citados durante este trabalho.

A linguística tem por objetivo o estudo da linguagem e não um método de ensino da língua portuguesa, fornecendo o conteúdo e as técnicas de investigação para orientar professores em seus programas e aulas, a fim de ampliar a competência comunicativa de seus alunos.

Cada aula deve ser considerada uma situação comunicativa diferente, e se for adequadamente explorada, pode produzir resultados eficientes e reais se o professor conseguir fazer as intervenções necessárias para estimular a compreensão e a aprendizagem dos alunos.

É na sala de aula que as diferenças se encontram e é ali que as situações de aprendizagem são construídas, mediadas pelo conhecimento e habilidade do professor.

Ignorar todas essas mudanças significa reforçar fracassos, reproduzir erros e acentuar diferenças sociais, tão longe do que se deseja alcançar com os estudos e pesquisas da língua que temos a disposição.

Esta pesquisa serve como reflexão inicial acerca do assunto, já que pretendo desenvolver minha tese de mestrado baseada nessa problemática: o ensino eficiente e significativo da gramática na educação básica da rede pública de ensino.

Dessa forma, este trabalho tem importância real e singular no caminho que ainda será percorrido nessa discussão, pois ainda há muito que pesquisar na realidade dessas escolas, que age de maneira discriminatória e displicente em relação a esta problemática.

\section{Referências bibliográficas}

CAGLIARI, Luiz Carlos. Alfabetização e Linguística. $1^{\mathrm{a}}$ Edição.São Paulo: Scipione, 2009. Pg. 16, 32

DUTRA, Vânia Lúcia Rodrigues.

Abordagem funcional da gramática na escola básica. Anais do VII Congresso Internacional de Abralin. Curitiba, 2011.

Disponível em: http://www.abralin.org/abralin11 _cdrom/artigos/Vania_Dutra.PDF. Acesso em 10 jan 2013. 
HALLIDAY, M. A. K. An introduction to functional grammar. London: Edward Arnold, 2004.

KATO, Mary A. No mundo da escrita: uma perspectiva psicolinguística. 7 edição. São Paulo: editora Ática, 2005, pg 28.

TRAVAGLIA, Carlos Luiz. Gramática e Interação: uma proposta para o ensino de gramática. 11. Ed. São Paulo: Cortez, 2006.

\section{Webgrafia}

TRAVAGLIA, Luiz Carlos. Ensino de gramática em uma perspectiva textualinterativa e qualidade de vida. Disponível em:

http://www.mel.ileel.ufu.br/homepages/tra vaglia/artigos/artigo_ensino _ gramatica _perspectiva_qualidade_vida.pdf. Acesso em 14 jan 2013.

http://portal.mec.gov.br/seb/arquivos/pdf /livro02.pdf/ pg. 60, Acesso em: 14 jan 2013

http://www4.uninove.br/ojs/index.php/dia logia/article/viewFile/847/727, pg 111.

Acesso em 16 jan 2013 